\title{
LOW NOX COMBUSTION OF DME BY EXHAUST GAS RECIRCULATION
}

\author{
Atsushi IKEDA*, Ryosuke MATAUMOTO* and Mamoru OZAWA* \\ *Dept. of Mech. Eng., Kansai University, 3-3-35, Yamatecho, Suita, Osaka 564-8680, Japan
}

\begin{abstract}
This study focuses on the fundamental characteristics of DME combustion aiming at the development of low-NOx combustion technology with exhaust gas recirculation (EGR) under high pressure. DME has high potential of applicability of exhaust gas recirculation even at the high mixing ratio because of its high burning velocity and low ignition temperature. Prior to the high pressure combustion test, the combustion test under an atmospheric pressure was conducted with laboratory-scale $11.6 \mathrm{~kW}$ combustor, where $\mathrm{O}_{2}$ concentration and temperature at the combustor inlet was systematically regulated, so that the exhaust-gas recirculation at various mixing ratios was simulated. The maximum EGR ratio is $91 \%$ at the initial air ratio $\lambda=1.5$ with preheated diluted air at $700 \mathrm{~K}$. The NOx emission reduced to $14 \mathrm{ppm}$, which is about $13 \%$ of that at $\mathrm{EGR}=0 \%$. The stable combustion sustains even at low oxygen concentration by preheating diluted-air. The exhaust gas recirculation is effective means especially for DME in reducing NOx emission drastically.
\end{abstract}

Keywords: DME (Dimethyl Ether), EGR (Exhaust Gas Recirculation), Diffusion Combustion, Gas Turbine

\section{Introduction}

Increasing attention has been focused on new alternative fuel, DME (Dimethyl ether), from the energy security and the environmental aspects for gas turbine fuel for electric power generations. DME is a new synthetic fuel and the most simple ether compound, expressed by the chemical formula $\mathrm{CH}_{3} \mathrm{OCH}_{3}$. Recently, the direct synthesis process of DME from $\mathrm{CO}$ and $\mathrm{H}_{2}$ are being reformed from the coal gasification [1]. Thus, DME can be produced from any kinds of carbon resources, such as natural gas, coal-bed methane associated in the coal mine.

The physical properties of DME are listed in Table 1 [2]. DME does not contain sulfur component and is quite suitable for diesel engine because of high cetane number and no emission of suspended particle matters. Adiabatic flame temperature is sufficiently high, but DME has rather low ignition temperature with high burning velocity compared with methane. The fact causes a difficulty in the use of use of the lean pre-mixed combustion system for low-NOx combustion of DME. Thus the burner should be, in principle, diffusion-type. In order to develop combustion technology of DME for gas turbines, it is essential to introduce alternative concept for low NOx combustion [3].

This study focuses on the fundamental characteristics of DME combustion aiming at development of low-NOx combustion technology with exhaust gas recirculation, EGR. The concept of the external exhaust gas recirculation is illustrated in Fig.1. The recirculated exhaust gas is introduced into the combustion chamber to control the oxygen concentration and the combustion gas temperature, so that NOx emission is significantly reduced. The exhaust gas recirculation at high mixing ratio, however, may lead to unstable combustion of conventional fuels, methane. On the other hand, DME has high potential of applicability of EGR even at the high mixing ratio because of its high burning velocity and low ignition temperature.

Copyright $\odot 2009$ by the Japan Society of Mechanical Engineering
Table 1 Physical properties of DME

\begin{tabular}{|c|c|c|c|}
\hline Property & $\mathrm{DME}$ & Propane & Methane \\
\hline Chemical Formula & $\mathrm{CH}_{3} \mathrm{OCH}_{3}$ & $\mathrm{C}_{3} \mathrm{H}_{8}$ & $\mathrm{CH}_{4}$ \\
\hline Boiling point, $\mathrm{K}$ & 248 & 231 & 112 \\
\hline Liquid density, g/cm & 0.67 & 0.49 & N.A. \\
\hline $\begin{array}{c}\text { Gas specific gravity relative } \\
\text { to air }\end{array}$ & 1.59 & 1.52 & 0.55 \\
\hline $\begin{array}{c}\text { Saturated vapor pressure, } \\
\text { atm at 298.15K }\end{array}$ & 6.1 & 9.3 & 246 \\
\hline Ignition temperature, $\mathrm{K}$ & 623 & 743 & 923 \\
\hline Cetane number & $55-60$ & 5 & 0 \\
\hline Net calorific value, $\mathrm{MJ} / \mathrm{m}^{3} \mathrm{~N}$ & 59.5 & 91.3 & 36 \\
\hline Net calorific value, $\mathrm{MJ} / \mathrm{kg}$ & 28.9 & 46.5 & 50.2 \\
\hline $\begin{array}{c}\text { Adiabatic flame } \\
\text { temperature, } \mathrm{K}\end{array}$ & 2227 & 2250 & 2236 \\
\hline Burning velocity, $\mathrm{cm} / \mathrm{s}$ & 50 & 43 & 37 \\
\hline Stoichiometric ratio, $\mathrm{m}^{3} / \mathrm{m}^{3}$ & 14.3 & 23.8 & 9.52 \\
\hline
\end{tabular}

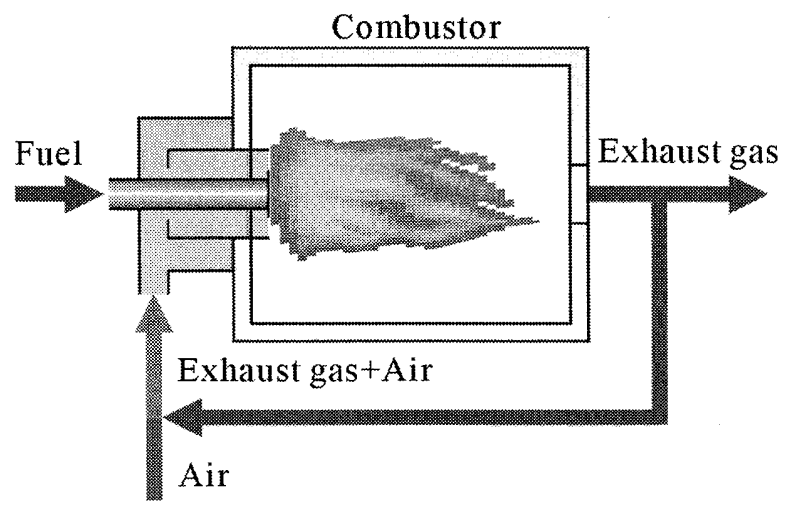

Fig.1 Schematic view of external exhaust gas recirculation 
In this study, the NOx emission characteristic of DME combustion with EGR is investigated under the high pressure. On the first stage of this study, the combustion test under the atmospheric pressure is carried out with laboratory scale of $11.6 \mathrm{~kW}$ combustor. In this experiment, oxygen concentration and temperature at the combustor inlet was systematically regulated, so that the exhaust gas recirculation at various mixing ratios was simulated. The blow off limits and the exhaust gas concentration were measured, and these results are compared with that of city gas 13A and LPG. Finally, NOx reduction ratio of laboratory scale combustor and industrial-scale boilers is discussed.

\section{Experimental apparatus}

Figure 2 shows the experimental setup of $8 \mathrm{~kW}$ combustor under the high pressure of $0.5 \mathrm{MPa}$. The flow rate of the fuel gas supplied at the room temperature was measured by a volumetric flow meter. The purity of the DME gas is $99.9 \%$. The city gas $13 \mathrm{~A}$ consists of methane of $88.9 \%$, ethane of $6.8 \%$, propane of $3.1 \%$ and butane of $1.2 \%$ and its low heating values is $40.4 \mathrm{MJ} / \mathrm{m}^{3}{ }_{\mathrm{N}}$. LPG consists of propane and propylene of $80 \%$, butane of $20 \%$ and its low heating value is $99 \mathrm{MJ} / \mathrm{m}^{3}{ }_{\mathrm{N}}$. To simulate the exhaust gas recirculation, the oxygen concentration and the temperature of combustion air were controlled by diluting with nitrogen gas preheated up with an electrical heater. Air and nitrogen flow rates were regulated by means of a mass flow meter, and were well-mixed in the gas mixer. The oxygen concentration of the combustion air was measured by $\mathrm{O}_{2}$ meter.

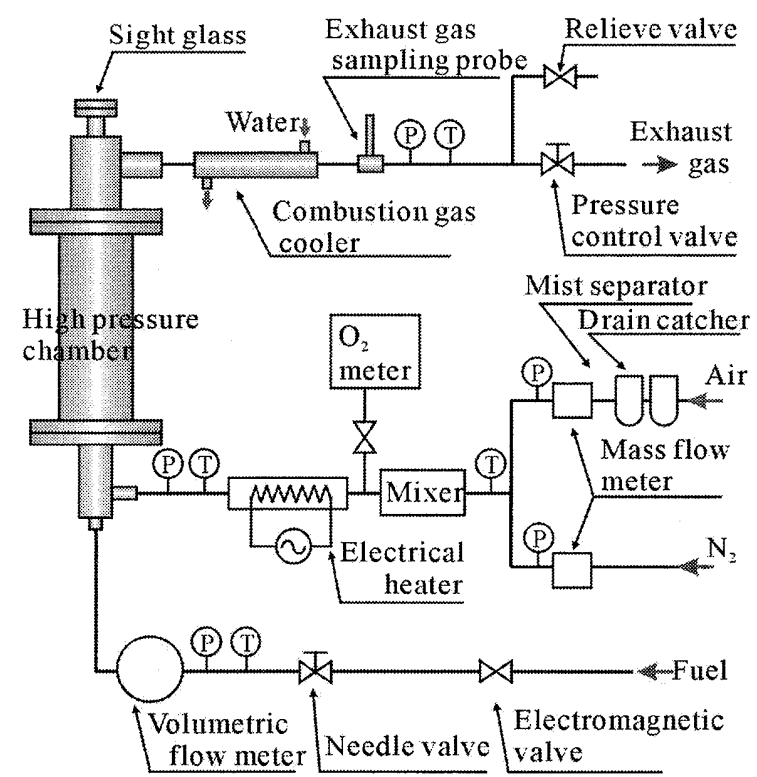

Fig.2 Experimental setup for high pressure combustion test.

The combustor, shown in Fig.3, consists of the multi-port diffusion burner and the combustion chamber. The combustion chamber is a cylindrical chamber of $123 \mathrm{~mm}$ in inner diameter and $400 \mathrm{~mm}$ in height. At the bottom of chamber, the diffusion burner is installed. The inner walls of the chamber are covered with fireproof materials. All the metallic parts of the setup consist of SUS304. The pressure of the combustion chamber is controlled by a pressure control valve.
The multi-port diffusion burner was designed by the authors to achieve well-mixed condition of fuel gas, steady and strong re-circulation followed by stable combustion and small but uniformly distributed flames [4]. The fuel gas was issued from the center hole and the combustion air was from small multiple ports placed around the fuel port.

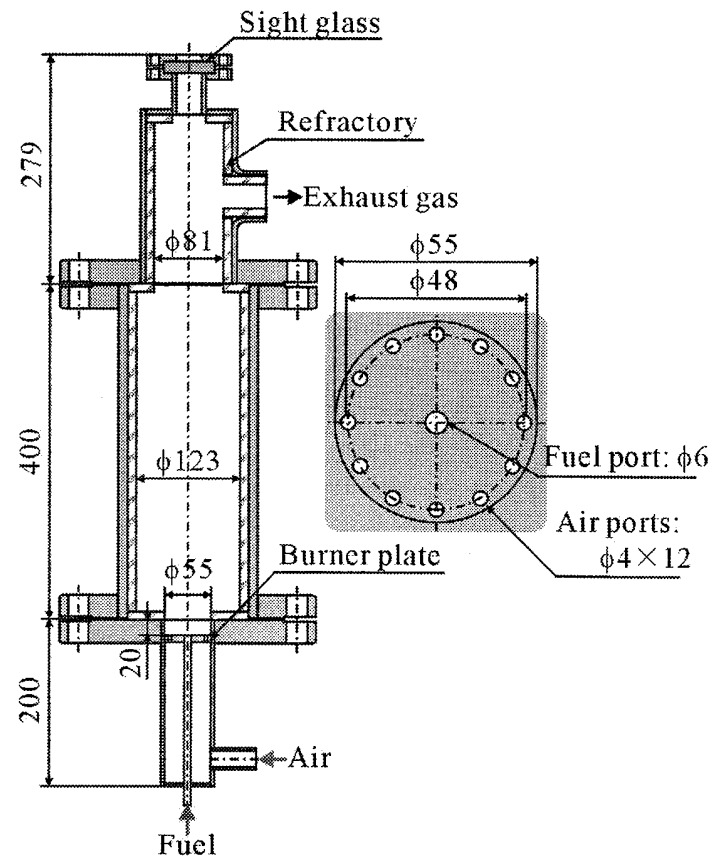

Fig.3 Combustion chamber and multi-port burner for the high pressure combustion test.

Fig.4 shows the combustion chamber for the atmospheric pressure. The combustion chamber has a cross-section of $100 \mathrm{~mm} \times 90 \mathrm{~mm}$ and $582 \mathrm{~mm}$ in height. The combustion gases were sampled at $530 \mathrm{~mm}$ from the burner exit by using a water-cooled sampling probe, and were analyzed with the gas analyzer (Horiba Corp. PG-235a). The $\mathrm{CO}, \mathrm{NOx}$ and $\mathrm{O}_{2}$ concentrations were measured by infrared absorption, chemiluminescence, and zirconia oxygen sensor, respectively. The gas temperature was measured by R-type thermocouple at the same position as the gas sampling.

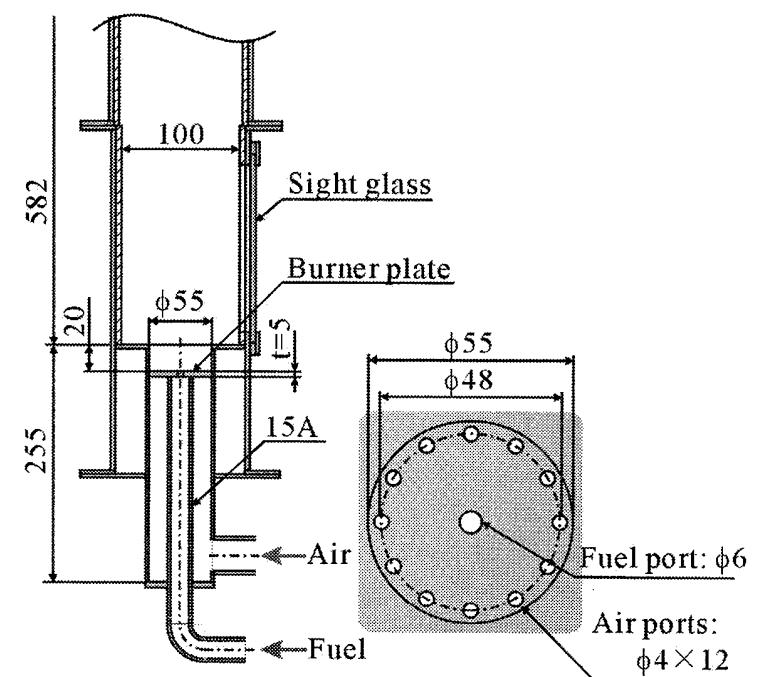

Fig. 4 Combustion chamber for the atmospheric pressure. 


\section{Estimation of the EGR simulation model} as follows;

Exhaust gas recirculation ratio, EGR ratio, is defined

$$
\text { EGR ratio }=\frac{\text { Flow rate of recirculat ion exhaust gas } V_{E G R}}{\text { Air flow rate } V_{\text {air }}}
$$

Equation (1) can be expressed as Eq.(2) by using the oxygen concentrations of the exhaust gas and the diluted air.

$$
\text { EGR ratio }=\frac{21 \%-\text { Diluted air } \mathrm{O}_{2} \%}{\text { Diluted air } \mathrm{O}_{2} \%-\text { Exhaust gas } \mathrm{O}_{2} \%}
$$

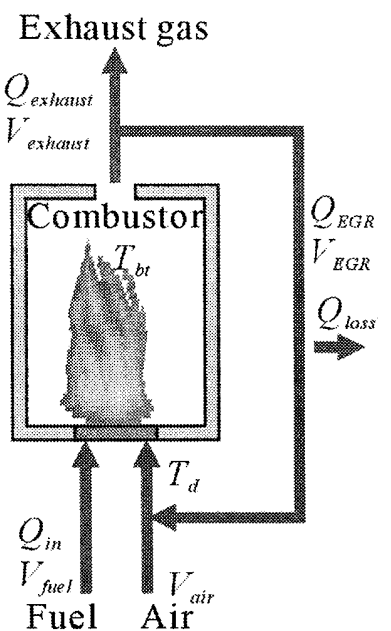

(a) Actual EGR

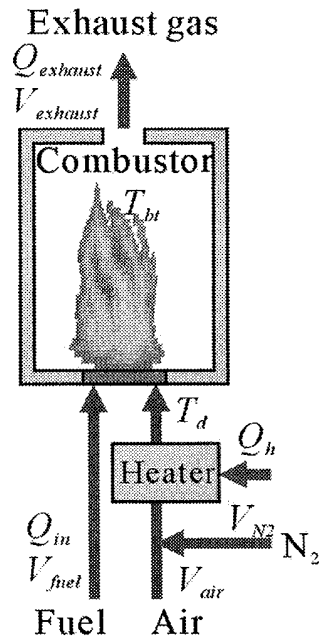

(b) EGR simulation
Fig.5 EGR models.

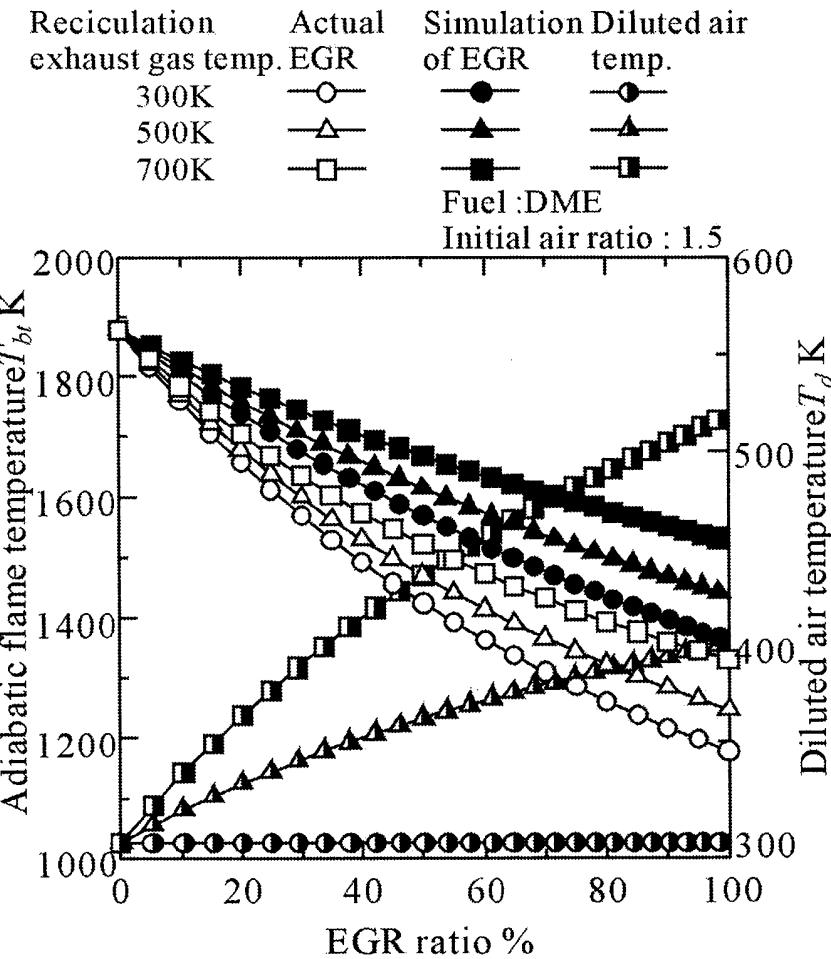

The exhaust gas recirculation suppresses the NOx emission by increasing the flow rate of the combustion gas to be reduced the flame temperature. The EGR models are shown in Fig.5. The flow rate of the diluted air is sum of the $V_{\text {air }}$ and $V_{E G R}$. On the actual EGR model, the flow rate of the diluted air becomes larger than that of the simulated EGR model at the same EGR ratio, due to the recirculated exhaust gas has several percent of oxygen concentration. Thus, the adiabatic flame temperature on the simulated EGR model has higher than that at the actual EGR model.

Figure 6 shows the adiabatic flame temperature to the EGR ratio at the various recirculation gas-temperature. The initial air ratio is $\lambda=1.5$. Adiabatic flame temperature decreases with increasing EGR ratio, while the adiabatic flame temperature increases by preheating diluted air, which is induced by increasing recirculation exhaust gas temperature. Because of difference of the flow rate of the combustion gas, the adiabatic flame temperature of EGR simulation is higher than that of actual EGR. This indicates that this experiment in this study simulates severe conditions for the NOx emission.

\section{Result and discussion of combustion tests}

Figure 7 shows the NOx and CO concentrations of the exhaust gas as a function of the air ratio $\lambda$ without the exhaust gas recirculation. The air ratio $\lambda$ is defined as the ratio of air volume relative to stoichiometric volume of air, i.e. the inverse of the equivalence ratio. The air ratio is approximately related to the $\mathrm{O}_{2}$ concentration of the exhaust gas by $\lambda=21 /\left(21-\mathrm{O}_{2}[\%]\right)$. The $\mathrm{NOx}$ emission decreases with increasing the air ratio on city gas $13 \mathrm{~A}$ and DME combustion, while the $\mathrm{CO}$ concentration is sufficiently low. The NOx emission is around $100 \mathrm{ppm}$ at the range of 1.2 to 1.6 of the air ratio in DME combustion, which is higher than that of the city gas and propane. The combustion tests with the simulated exhaust gas recirculation were carried out based on the air ratio 1.2 and 1.5 .

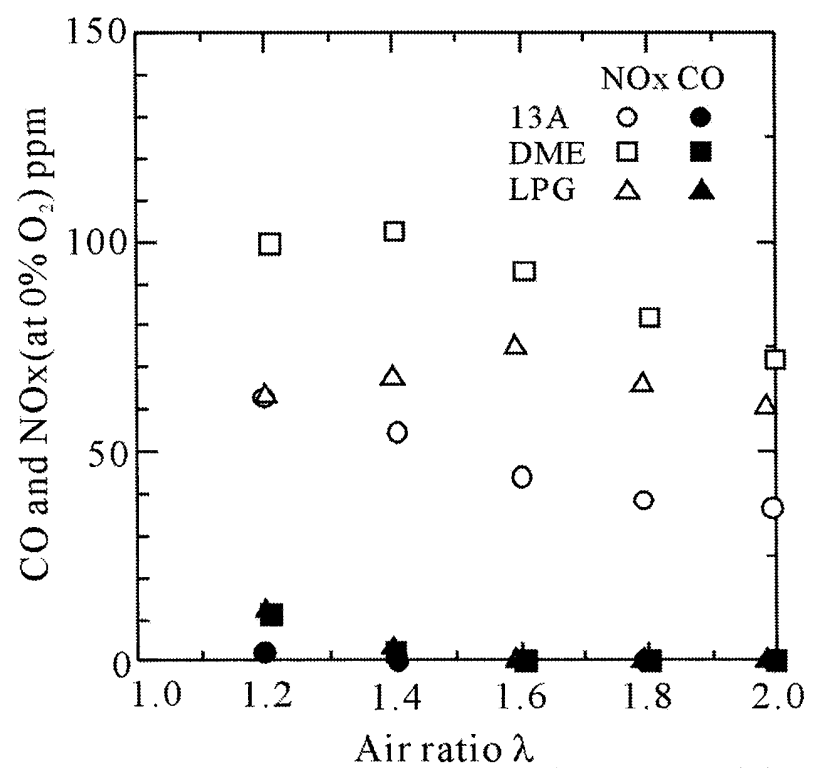

Fig.7 Exhaust gas concentrations without EGR at inlet air temperature of $300 \mathrm{~K}$.

Fig. 6 Calculation result of EGR. 
Figure 8, 9 and 10 show the results of the city gas, DME and propane combustion tests with exhaust gas recirculation. Experiments were carried out by changing the flow rate of nitrogen gas, which corresponds to the exhaust gas recirculation ratio, EGR ratio. In this experiment, the EGR ratio is estimated from the measured $\mathrm{O}_{2}$ concentrations of the exhaust gas and diluted combustion air, i.e., $\mathrm{O}_{2}$ concentration of the combustion air.

Figure 8 shows the combustion test of the city gas at the air ratio $\lambda=1.5$. The NOx concentration decreased successively with increasing the EGR ratio, while the flame blow-off occurred at $18 \%$ of EGR ratio when the inlet temperature of the combustion air was at $300 \mathrm{~K}$.

By imposing the exhaust gas recirculation, the low oxygen concentration causes the slow heat release in the combustion chamber. The flame temperature shows relatively mild temperature distribution and the local hot spot is avoided from the flame [5]. Thus, the exhaust gas recirculation is an effective method to reduce the NOx emission. However, combustion with the low-oxygen concentration usually becomes unstable. By preheating the diluted air to $700 \mathrm{~K}$, the stable combustion can be achieved and the flame blow-off extended to at $50 \%$ of the EGR ratio, as shown in Fig.8. In the actual exhaust gas recirculation, the combustion air is preheated by mixing with the high temperature exhaust gas.

On the DME combustion at the air ratio $\lambda=1.5$, the blow off limitation is extended to higher EGR ratio than that of city gas, as shown in the Fig.9. The blow-off occurred at $47 \%$ of EGR ratio for $300 \mathrm{~K}$. By preheating the diluted air to $700 \mathrm{~K}$, the blow-off observed at $93 \%$ of EGR ratio. The NOx concentration drastically reduced to $14 \mathrm{ppm}$ at $0 \%-\mathrm{O}_{2}$ for $90 \%$ of EGR ratio with $700 \mathrm{~K}$ of the preheating diluted air. This indicates that DME has a high possibility of reducing NOx emission by means of EGR. Such characteristic may be due to the high burning velocity and low auto-ignition temperature.

On the LPG combustion at the air ratio $\lambda=1.5$, the blow-off limitation is contracted to lower EGR ratio than that of DME, as shown in the Fig.10. The blow-off occurred at $33 \%$ of EGR ratio for $300 \mathrm{~K}$. By preheating the diluted air to $700 \mathrm{~K}$, the blow-off observed at $80 \%$ of EGR ratio. The NOx concentration decreased as well as at city gas and DME with increasing the EGR ratio.

The blow-off limits of the flame at combustion rate of $8 \mathrm{~kW}$ are plotted in the relationship between the $\mathrm{O}_{2}$ concentration and inlet temperature of the diluted air in Fig.11. The stable combustion is realized in the left-side area of the blow-off limit expressed by solid lines. The blow-off limit is a function of the oxygen concentration of diluted air independent of the air ratio. By preheating the diluted air, the stable combustion range becomes wide. DME has a wider stable combustion range than that of the city gas and LPG. M. Katsuki et al propane blow-off limit expressed by dashed-dotted line [5]. Though it is not possible to compare directly with experimental result of this study by difference of such as burner, it is shown that the stable combustion is possible in extremely low oxygen concentration of $10 \%$ by preheating diluted air. The auto-ignition temperature of DME is $623 \mathrm{~K}$ expressed by horizontal dash line, which is lower than that of methane $923 \mathrm{~K}$ and propane $743 \mathrm{~K}$. Though diluted air is preheated

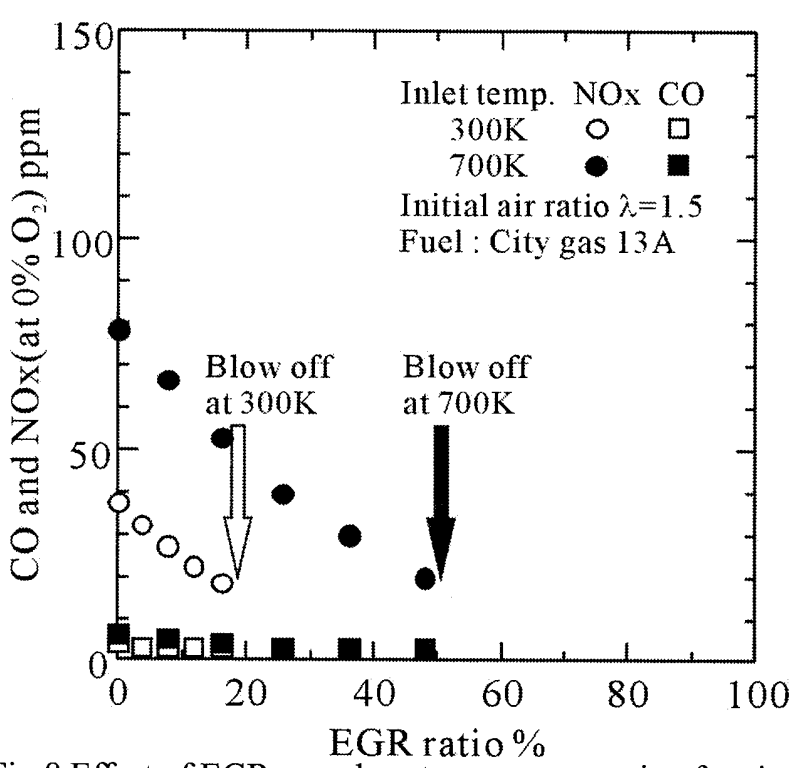

Fig.8 Effect of EGR on exhaust gas concentration for city gas $13 \mathrm{~A}$ combustion, $\lambda=1.5$.

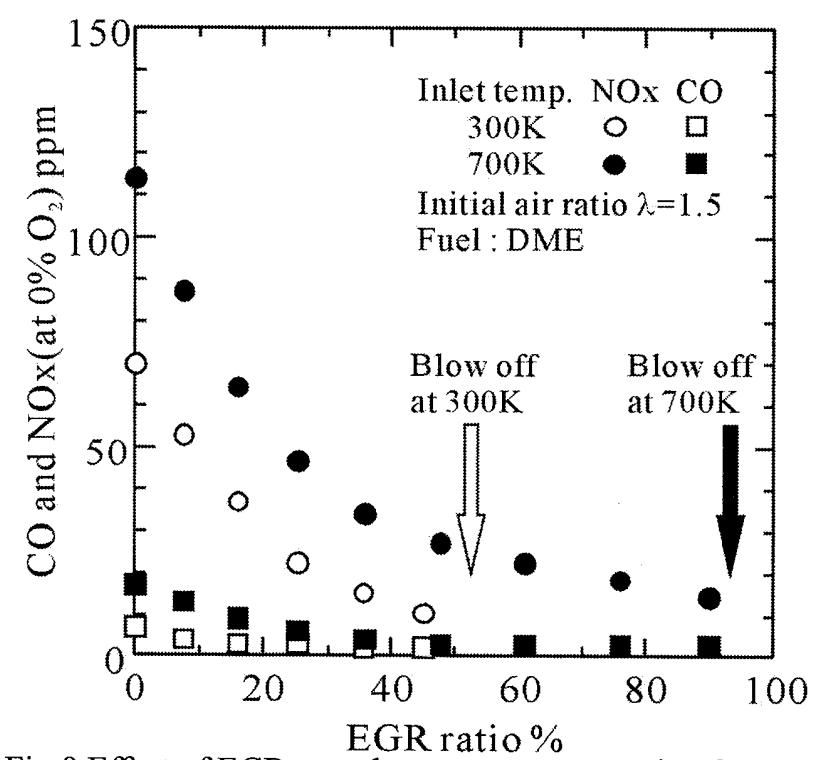

Fig.9 Effect of EGR on exhaust gas concentration for DME combustion, $\lambda=1.5$.

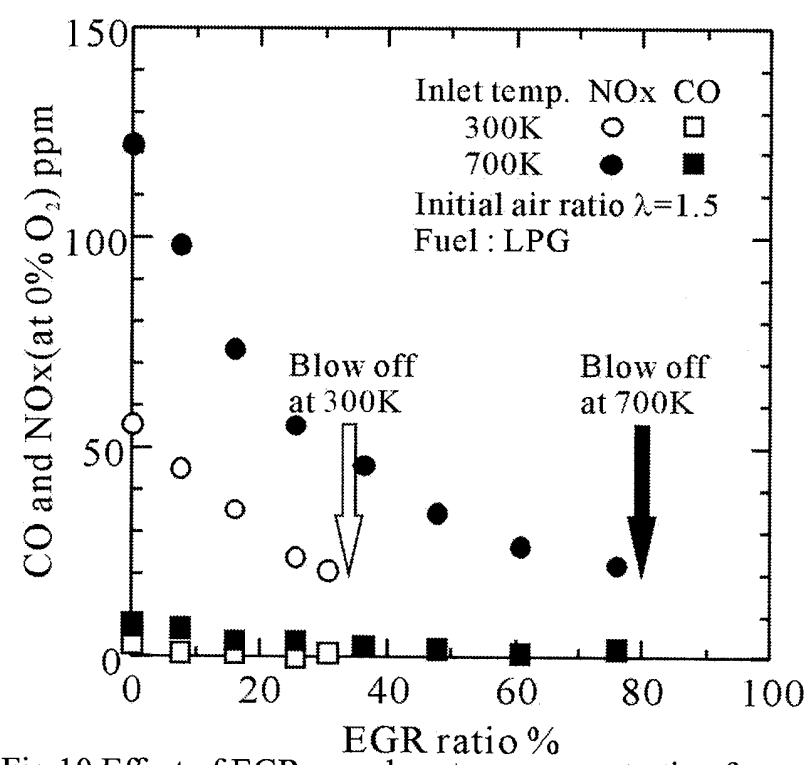

Fig. 10 Effect of EGR on exhaust gas concentration for LPG combustion, $\lambda=1.5$. 


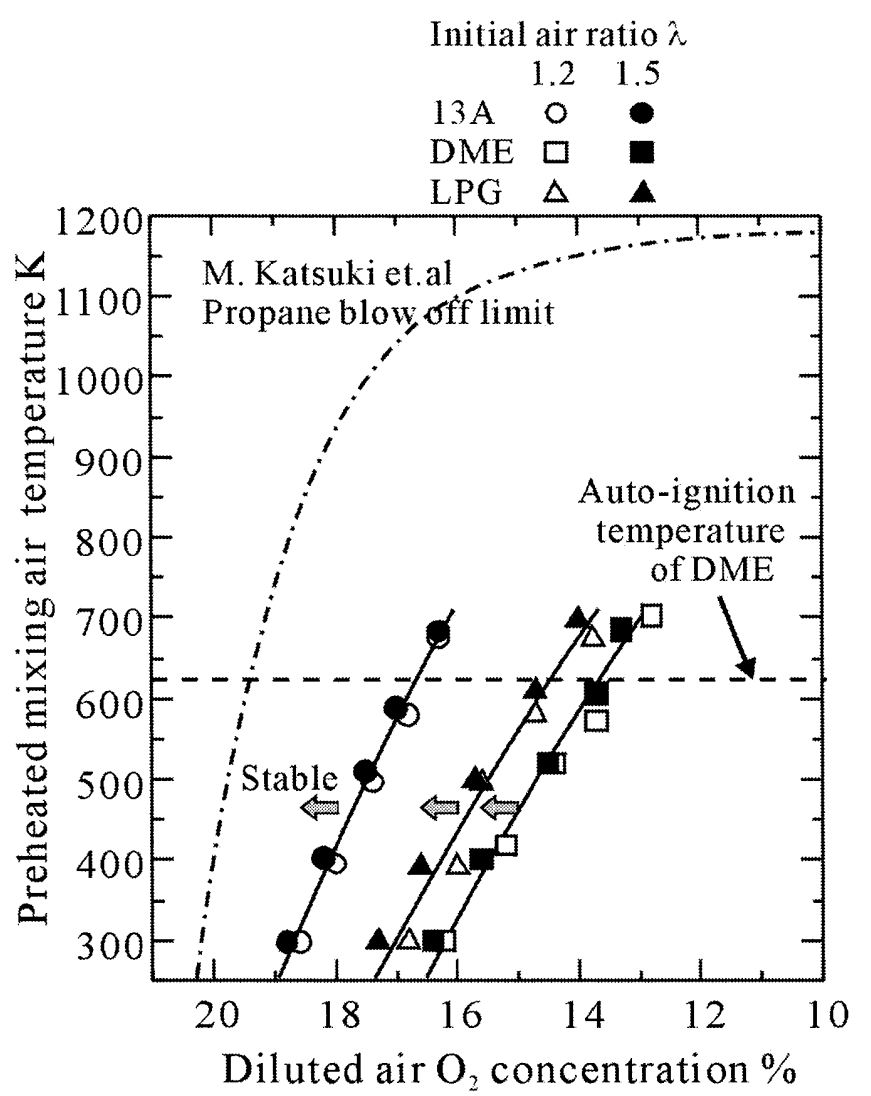

Fig.11 Stable combustion range combustion rate of $8 \mathrm{~kW}$. (Plots shows the blow off limt.)

over the auto-ignition temperature of DME, stable combustion range did not extended greatly.

Figure 12 shows the NOx reduction ratio relative to the case without EGR. The plotted data includes all result of $11.6 \mathrm{~kW}$ laboratory-scale combustion tests and industrial-scale boilers of $700 \mathrm{~kW}$-class (1ton/hour steam output) and $7 \mathrm{MW}$-class (10ton/hour steam output). These two boilers have been developed by Hirakawa Guidom Co. Ltd. in the framework of R\&D project for DME used by METI [6], [7], [8]. The detailed description is found elsewhere [9]. Fundamental design of these boilers is based on the tube-nested combustion aiming at the effective low-NOx combustion. The tube-nested combustor [10] consists of the water tube in its furnace to cool the burning flame directly in the field of burning reaction. Agitation of the burning flame with the installed water-tube-nest enhances combustion and brings about a uniform flame temperature distribution leading to further NOx reduction. Further detailed description on the tube-nested combustor was described in the previous report [7]. In $11.6 \mathrm{~kW}$ laboratory-scale combustion tests, DME is applicable even up to the high EGR ratio of $90 \%$, and the NOx emission reduced about $13 \%$ of that at $0 \%$ of EGR ratio. In addition, all the experimental data falls into a single curve. In industrial-scale boilers, on the other hand, the NOx reduction ratio shows the similar trend in spite of the difference in the burning capacity. The NOx emission drastically decreases with EGR ratio until about $50 \%$ of EGR, while decreasing moderately over $50 \%$ of EGR and the reduction is almost $10 \%$ compared with the case of NOx emission without EGR.

Above-mentioned results of experiment under the
$11.6 \mathrm{~kW}$ combustion test $700 \mathrm{~kW}$-class boiler

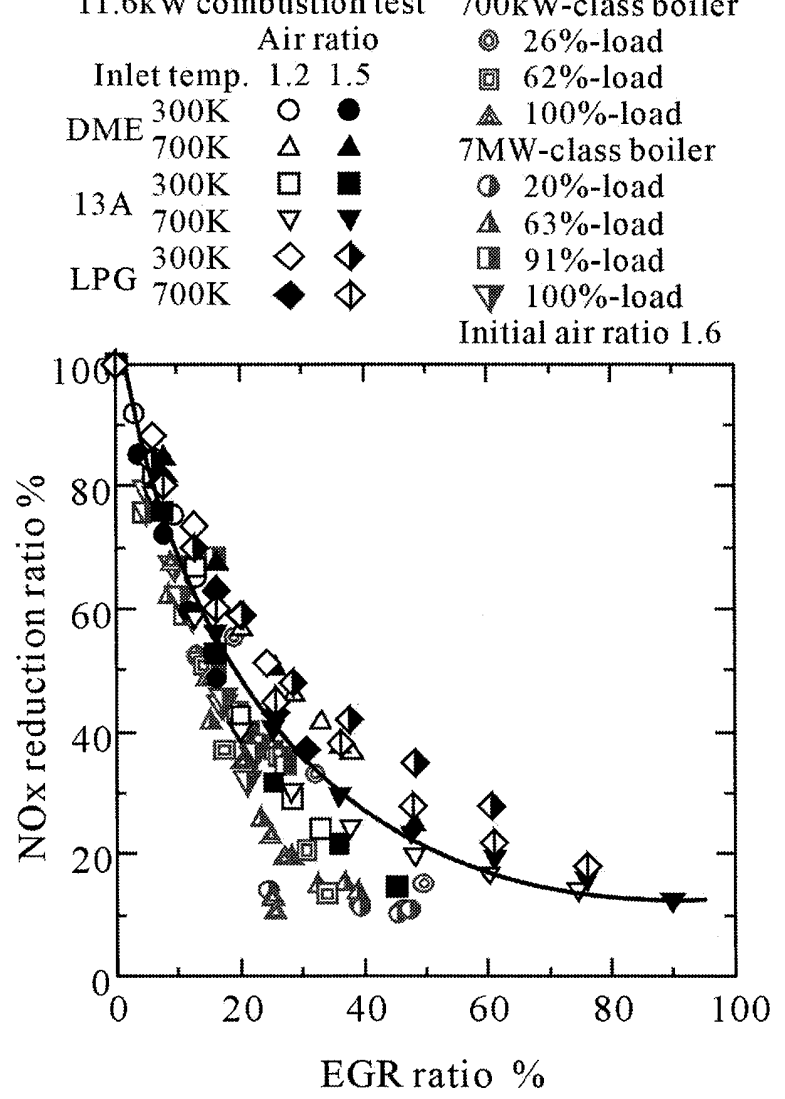

Fig.12 NOx reduction ratio on $11.6 \mathrm{~kW}$ combustion test, $700 \mathrm{~kW}$ and $7 \mathrm{MW}$-class test boiler.

atmosphere pressure indicate that the exhaust gas recirculation is effective means especially for DME in reducing NOx emission drastically. For the future, combustion tests under the high pressure will be conducted to investigate the $\mathrm{NOx}$ emission characteristic of DME combustion with exhaust gas recirculation. The results will be presented at ICOPE-09.

\section{Conclusions}

This study focuses on the fundamental characteristics of DME combustion with exhaust gas recirculation. Combustion tests were conducted with laboratory-scale $11 \mathrm{~kW}$ combustor under a atmospheric pressure as the preliminary test. The results are summarized as follows:

(1) EGR simulation experiment is carried out under the severe conditions for the NOx emission than the actual EGR.

(2) The NOx emission is lowered to $14 \mathrm{ppm}$ at high EGR ratio of $90 \%$. Such a high EGR ratio corresponds to decreasing the $\mathrm{O}_{2}$ concentration. This is mainly because of the high burning velocity and low ignition temperature of DME together with the enthalpy recirculation from the exhaust gas.

(3) In term of NOx reduction ratio and EGR ratio, there exists a similarity law effective in the larger scale low NOx combustor.

\section{Acknowledgement}

Authors wish to express their sincere thanks Mr. Y. Kondou and Mr. S. Fujimura. This study was conducted 
under the support by JFE Holdings, Inc. and Hirakawa Guidom Corp.

\section{References}

1. Ohno, Y., Ogawa, T., Shikada, T. and Inoue, N., DME Production Technology and Operation Results of 5 tons/day Plant, Proceedings of the International DME workshop, Japan DME Forum, (2000), pp.73-81.

2. Japan DME Forum, DME Handbook, (2006), pp.30-57, Ohmsha.

3. Kobayashi, N., Inoue, H., Koizumi, H. and Watanabe, T., Robust design of the coaxial jet cluster nozzle burner for DME (Dimethyl Ether) fuel, Proceedings of ASME Turbo Expo 2003, CD-ROM, (1993), GT2003-38410.

4. Matsumoto, R., Ozawa, M., Ishihara, I., Sasaki, S. and Takaichi, M., Development of low-NOx DME multi-port burner, JSME International Journal, Series $B$, Vol.49, No.2 (2006), pp. 245-252.

5. Gupta, A.K., Hasegawa, T., Katsuki, M., Kishimoto, K., Morita, M. and Tsuji, H., High Temperature Air Combustion: From Energy Conservation to Pollution Reduction, (2006), pp.1-28, CRC Press.
6. Ozawa, M., Matsumoto, R., Higuchi, N., Hayashi, Y., Uematsu, H. and Suita, Y., Low NOx Combustion Technology for DME-Fired Water-Tube Boiler, First International DME Conference-Conference Documentation-, (2004), 7B-3.

7. Ozawa, M., Matsumoto, R., Higuchi, N., Hayashi, Y., Uematsu, H. and Suita, Y., DME-Fired Water-tube Boiler - A R\&D Study, JSME International Journal, Series B, Vol.49, No.2 (2006), pp.253-259.

8. Ozawa, M. and Matsumoto, R., R\&D study for DME-fired low-NOx boiler, 2nd International DME conference -Conference Documentation-, (2006), 7b-2.

9. Seko, T., Matsumoto, R., Shintani, Y., Ishihara, I. and Ozawa, M., Diffusion Combustion in a Tube-Nested Combustor, JSME International Journal, Series B, Vol.47, No.2 (2004), pp.207-213.

10. Ueda, Y., Ishigai, S., Ozawa, M., Kurimoto, K., Hasebe, H. Okada, H., Kaminashi, A., Kinoshita, M and Yamamoto, M., Experimental Study of a New Type Boiler with Tube-Nested Combustor, Proceedings of ICOPE'95 Shanghai, (1995), pp.357-362. 